\title{
TWIST1 CONTROLS CELLULAR SENESCENCE AND ENERGY METABOLISM IN MESENCHYMAL STEM CELLS
}

\author{
C. Voskamp ${ }^{1}$, L.A. Anderson, W.J.L.M. Koevoet², S. Barnhoorn ${ }^{3}$, P.G. Mastroberardino ${ }^{3}$, G.J.V.M. van Osch ${ }^{1,2}$ \\ and R. Narcisi ${ }^{1, *}$
}

${ }^{1}$ Department of Orthopaedics and Sports Medicine, Erasmus MC, University Medical Centre Rotterdam, 3015 CN Rotterdam, the Netherlands

${ }^{2}$ Department of Otorhinolaryngology, Erasmus MC, University Medical Centre Rotterdam, 3015 CN Rotterdam, the Netherlands

${ }^{3}$ Departments of Molecular Genetics, Erasmus MC, University Medical Centre Rotterdam, 3015 CN Rotterdam, the Netherlands

\begin{abstract}
Mesenchymal stem cells (MSCs) are promising cells for regenerative medicine therapies because they can differentiate towards multiple cell lineages. However, the occurrence of cellular senescence and the acquiring of the senescence-associated secretory phenotype (SASP) limit their clinical use. Since the transcription factor TWIST1 influences expansion of MSCs, its role in regulating cellular senescence was investigated. The present study demonstrated that silencing of TWIST1 in MSCs increased the occurrence of senescence, characterised by a SASP profile different from irradiation-induced senescent MSCs. Knowing that senescence alters cellular metabolism, cellular bioenergetics was monitored by using the Seahorse XF apparatus. Both TWIST1-silencing-induced and irradiation-induced senescent MSCs had a higher oxygen consumption rate compared to control MSCs, while TWIST1-silencing-induced senescent MSCs had a low extracellular acidification rate compared to irradiation-induced senescent MSCs. Overall, data indicated how TWIST1 regulation influenced senescence in MSCs and that TWIST1 silencing-induced senescence was characterised by a specific SASP profile and metabolic state.
\end{abstract}

Keywords: Mesenchymal stem cells, cellular senescence, secretory phenotype, regenerative medicine, metabolism.

*Address for correspondence: Roberto Narcisi, PhD, Department of Orthopaedics and Sports Medicine, Erasmus MC, 3015 CN Rotterdam, the Netherlands.

Email: r.narcisi@erasmusmc.nl

Copyright policy: This article is distributed in accordance with Creative Commons Attribution Licence (http://creativecommons.org/licenses/by-sa/4.0/).

\begin{tabular}{|c|c|c|c|}
\hline & \multirow[t]{2}{*}{ List of abbreviations } & GFP & green fluorescent protein \\
\hline & & $\mathrm{HG}$ & high glucose \\
\hline$\alpha \mathrm{MEM}$ & $\begin{array}{l}\text { minimum essential medium alpha } \\
\text { modification }\end{array}$ & HPRT1 & $\begin{array}{l}\text { hypoxanthine-guanine } \\
\text { phosphoribosyltransferase }\end{array}$ \\
\hline ATP & adenosine tri-phosphate & IL & interleukin \\
\hline BHI & best housekeeping index & MiDAS & mitochondrial dysfunctional \\
\hline CCL2 & chemokine ligand 2 & & senescence \\
\hline CDKN & cyclin-dependent kinase inhibitor & MMP & matrix metalloproteinase \\
\hline $\mathrm{Ct}$ & cycle threshold & MSC & mesenchymal stem cell \\
\hline $\begin{array}{l}\text { DMEM } \\
\text { ECAR }\end{array}$ & $\begin{array}{l}\text { Dulbecco's modified Eagle medium } \\
\text { extracellular acidification rate }\end{array}$ & NADH & $\begin{array}{l}\text { 1,4-dihydronicotinamide adenine } \\
\text { dinucleotide }\end{array}$ \\
\hline FCCP & fluoro-carbonyl cyanide & nc & nucleated cells \\
\hline & henylhydrazone & OCR & oxygen consumption rate \\
\hline FGF2 & basic fibroblast growth factor & PBS & phosphate-buffered saline \\
\hline GAPDH & $\begin{array}{l}\text { glyceraldehyde 3-phosphate } \\
\text { dehydrogenase }\end{array}$ & $\begin{array}{l}\text { RPS27A } \\
\text { rtTA }\end{array}$ & $\begin{array}{l}\text { ribosomal protein } \mathrm{S} 27 \mathrm{a} \\
\text { reverse Tet transactivator }\end{array}$ \\
\hline
\end{tabular}




$\begin{array}{ll}\text { SA- } \beta \text {-gal } & \begin{array}{l}\text { senescence-associated } \\ \beta \text {-galactosidase } \\ \text { senescence-associated secretory } \\ \text { phenotype } \\ \text { standard deviation }\end{array} \\ \text { SD } & \begin{array}{l}\text { twist family bHLH transcription } \\ \text { factor } 1\end{array} \\ \text { TWIST1 } & \text { vascular endothelial growth factor } \\ \text { VEGF } & \text { vesicular stomatitis virus G } \\ \text { VSV-G } & \text { Wnt family member 3a } \\ \text { WNT3a } & \end{array}$

\section{Introduction}

Regenerative medicine strategies aim to regenerate tissues that have been damaged by injury or pathology. A promising cell source for regenerative medicine therapies is the multipotent progenitor cell referred to as MSC. MSCs have the capacity to self-renew and differentiate towards multiple lineages (Pittenger et al., 1999); moreover, they can be isolated from several tissues (Erices et al., 2000; Halvorsen et al., 2000; Haynesworth et al., 1992; Pittenger et al., 1999; Romanov et al., 2003; Zuk et al., 2001). However, a limitation that hinders the clinical use of MSCs is their inter- and intra-donor variability in differentiation capacity. This heterogeneity includes the occurrence of cellular senescence ( $\mathrm{Li}$ et al., 2017). Cellular senescence is an irreversible state in which cells undergo permanent cell cycle arrest, while they are still metabolically active and can secrete pro-inflammatory factors. Senescence is generally induced by replicative exhaustion, DNA damage, oncogenes or mitochondrial dysfunction (Kumari and Jat, 2021). The pool of factors secreted by senescent cells define the so called SASP (Lunyak et al., 2017); their occurrence is linked to the metabolic state of the cell (Dörr et al., 2013; Wiley et al., 2016) and to the kind of stressor responsible for inducing senescence (Kumari and Jat, 2021). Typical SASP genes common to most senescent cells are $I L 1 B, I L 6$, MMPS, CCL2 and VEGF. Glycolysis, which breaks down glucose into pyruvate, ATP and NADH, has been demonstrated to be increased in senescent cells (Bittles and Harper, 1984; James et al., 2015). In addition, senescent fibroblasts can have an impaired mitochondrial metabolism (Wiley et al., 2016).

Cellular senescence has been shown to reduce the differentiation capacity of umbilical-cord-derived MSCs (Cheng et al., 2011) and could also be unsafe for regenerative medicine strategies, since senescent MSCs can promote tumour formation (Hochane et al., 2017; Li et al., 2015). In addition, senescent cells are known to contribute to tissue degeneration, since senescent cells transplanted into a mouse knee joint can induce an osteoarthritis-like phenotype showing reduced cartilage content, osteophyte formation and subchondral bone structure alterations ( $\mathrm{Xu}$ et al., 2017). Safe and reproducible clinical use of MSCs requires a better understanding of the molecular mechanisms behind cellular senescence and their SASP profile.

MSC expansion has been associated with the expression of the transcription factor TWIST1 (Isenmann et al., 2009; Narcisi et al., 2015; Voskamp et al., 2020). Moreover, TWIST1 can regulate the expression of the cellular senescence marker p21 in hypoxic MSC cultures (Tsai et al., 2011) and loss-offunction mutation of TWIST1 in Saethre-Chotzen patient cells results in accelerated senescence (Cakouros et al., 2012). The present study showed that TWIST1 overexpression in MSCs inhibited cellular senescence, while silencing of TWIST1 induced cellular senescence. In addition, TWIST1 could modulate the SASP and the bioenergetic profile in senescent MSCs, differently from senescence induced by irradiation. These results offered novel molecular insights in SASP and metabolism regulation and suggested that TWIST1 could be a target to modulate cellular senescence.

\section{Materials and Methods}

\section{Cell culture}

MSCs were isolated from leftover iliac crest bone chip material (9-13 years old patients) as previously described (Knuth et al., 2018), in accordance with the Medical Ethical Commission of the Erasmus MC (protocol number MEC-2014-16). No morphological differences were observed between MSCs from different donors at passage 0 (P0). Cells from the selected donors represented a starting population of MSCs with a low number of senescent cells $(<10 \%$ positivity for $\beta$-galactosidase, data not shown). MSCs were expanded in $\alpha \mathrm{MEM}$ (Gibco) containing $10 \%$ foetal calf serum (Gibco, selected batch 41Q2047K), $1.5 \mu \mathrm{g} / \mathrm{mL}$ fungizone (Invitrogen), $50 \mu \mathrm{g} / \mathrm{mL}$ gentamicin (Gibco), $0.1 \mathrm{mmol} / \mathrm{L}$ ascorbic acid (SigmaAldrich) and $1 \mathrm{ng} / \mathrm{mL}$ FGF2 (Instruchemie, Delftzijl, the Netherlands). MSCs were cultured at a density of 2,300 cells $/ \mathrm{cm}^{2}$ at $37{ }^{\circ} \mathrm{C}$ and $5 \% \mathrm{CO}_{2}$. Cells were trypsinised and medium changed twice a week. Depending on the assay and the experimental plan, passage 3 (P3) to passage 7 (P7) cells were used. Cells at P3 (with high TWIST1 expression) were used for the irradiation and silencing experiments to better appreciate the effect of TWIST1 downregulation compared to control. Cells at P7 (with lower TWIST1 expression) were used for the overexpression experiment to better appreciate the effect of TWIST1 upregulation compared to controls.

\section{TWIST1 silencing}

To study whether silencing of TWIST1 induced cellular senescence, low passage (P3-P4) MSCs were used. MSCs were seeded at a density of $2,300 \mathrm{cells} / \mathrm{cm}^{2}$ and cultured for $24 \mathrm{~h}$ in standard expansion medium. Next, cells were either treated with $15 \mathrm{nmol} / \mathrm{L}$ TWIST1 (4390824, Ambion) or scramble (4390843, Ambion) 
siRNA in combination with Lipofectamine RNAMAX Transfection Reagent (1:1,150; Invitrogen) and optiMEM (1:6; Gibco) or left untreated. The treatment was repeated every 3-4 d for 13-14 d.

\section{Lentiviral constructs and virus generation}

To study the effect of TWIST1 overexpression upon MSC senescence, tetracycline-inducible lentiviral constructs of TWIST1 and GFP were used. TWIST1 cDNA was cloned into a lentiviral construct under the control of the tetracycline operator. The GFP lentiviral vector was a gift from Marius Wernig's laboratory (Stanford School of Medicine, Stanford, CA, USA; Addgene plasmid \#30130). An empty lentiviral construct was used as a control. Third generation lentiviral particles with a VSV-G coat were generated in HEK293T cells. HEK293T cells were cultured in DMEM HG GlutaMAX (Life Technologies) containing $10 \%$ foetal calf serum, $1 \mathrm{mmol} / \mathrm{L}$ sodium pyruvate (Life Technologies) and 1:100 non-essential amino acids (Life Technologies) and seeded in poly-L-ornithine-coated plates at a density of $5 \times 10^{6}$ cells per $10 \mathrm{~cm}$ diameter dish. After $24 \mathrm{~h}$, cells were transfected with one of the lentiviral packaging vectors PMDL (5 $\mu$ g per $10 \mathrm{~cm}$ diameter dish), RSV (2.5 $\mu \mathrm{g}$ per $10 \mathrm{~cm}$ dish diameter) or VSV ( $2.5 \mu \mathrm{g}$ per $10 \mathrm{~cm}$ diameter dish) and one of the experimental inserts rtTA, TWIST1, GFP or an empty vector (10 $\mu$ g per $10 \mathrm{~cm}$ diameter dish) using polyethylenimine (1:166). Medium was changed $6 \mathrm{~h}$ post-transfection. Viral supernatants were filtered through a $0.45 \mu \mathrm{m}$ filter $24 \mathrm{~h}$ after the last medium change and stored at $-80^{\circ} \mathrm{C}$ until use.

\section{Lentiviral transduction}

To study whether TWIST1 overexpression inhibited cellular senescence, high passage (P7) MSCs were used. The transduction efficiency was determined by titration of the GFP lentivirus construct using different virus concentrations, 1:1:1, 1:1:3 and 1:1:8 of GFP:rtTA:MSC expansion medium. After transduction for $16 \mathrm{~h}$, cells were washed with PBS and fresh expansion medium supplemented with $2 \mu \mathrm{g} / \mathrm{mL}$ doxycycline (Sigma-Aldrich) was added. The transduction efficiency was assessed by analysis of the percentage of GFP positive cells using fluorescent microscopy and flow cytometry. For flow cytometry analysis, GFP-transduced MSCs were fixed in $2 \%$ formaldehyde (Fluka) and filtered through $70 \mu \mathrm{m}$ filters. Untransduced MSCs were used as a negative control. Samples were analysed by flow cytometry using a BD LSRFortessa ${ }^{\mathrm{TM}}$ Cell Analyzer (BD Biosciences). Data were analysed using FlowJo V10 software.

\section{mRNA analysis}

For each experiment involving RNA evaluation, the medium was changed $24 \mathrm{~h}$ before cell harvesting. MSCs were washed with PBS and lysed in RLT buffer containing $1 \% \beta$-mercaptoethanol. Subsequently,
RNA was isolated from the cells using the RNeasy micro kit (Qiagen) according to the manufacture's' instructions. cDNA was synthesised using the RevertAid First-Strand cDNA Synthesis Kit (Thermo Fisher Scientific). Real-time polymerase chain reactions were performed using TaqMan ${ }^{\mathrm{TM}}$ Universal PCR MasterMix (FAM + TAMRA chemistry; Applied Biosystems) or SYBR Green MasterMix (Fermentas) using a CFX96TM PCR detection system (Bio-Rad). The following thermal protocol was used: $10 \mathrm{~min}$ at $95^{\circ} \mathrm{C}+40$ cycles consisting of $15 \mathrm{~s}$ at $95^{\circ} \mathrm{C}$ followed by $1 \mathrm{~min}$ at $60^{\circ} \mathrm{C}$ as annealing step, except for CDKN2A (p16), CDKN1A (p21) and CCL2, which needed an annealing temperature of $61.5^{\circ} \mathrm{C}$. The melting curve protocol consisted of ramping from $65^{\circ} \mathrm{C}$ to $95^{\circ} \mathrm{C}$ with an increase of $0.5^{\circ} \mathrm{C} / \mathrm{min}$. Primers are listed in Table 1 and housekeeping genes GAPDH, HPRT1 and RPS27A were chosen for their stable expression in MSCs. The BHI, the geometric mean of the three housekeeping genes, was calculated according to the $\left(\mathrm{Ct}^{G A P D H} \times \mathrm{Ct}^{H P R T} \times \mathrm{Ct}^{R P S 27 A}\right)^{1 / 3}$ formula (Pfaffl et al., 2004). Each primer used was validated to generate a unique melting peak. Data were visualised based on the $2^{-\Delta C t}$ method.

\section{Irradiation-induced senescence}

Irradiation-induced senescence of MSCs was performed by a 20 Gray protocol (20 Gy) using ionising radiation by a RS320 X-Ray machine (X-Strahl, Camberley, UK). P3 MSCs at 60-70\% confluence in T175 flasks were used for the irradiation protocol. Cells were exposed for $22 \mathrm{~min}$. After irradiation, cells were left in the flask for $48 \mathrm{~h}$, trypsinised, seeded at 9,600 $\mathrm{nc} / \mathrm{cm}^{2}$ and cultured for another 3-5 d to allow for senescence to occur. At day 7 post irradiation $\beta$-galactosidase staining was performed. Control cells underwent the same protocol and exposed to a $0 \mathrm{~Gy}$ irradiation. Following trypsinisation, they were re-seeded at $2,300 \mathrm{nc} / \mathrm{cm}^{2}$.

\section{SA- $\beta$-gal staining}

Cells were washed twice with PBS and fixed with $0.5 \%$ glutaraldehyde and $1 \%$ formalin in Milli-Q water. Then, cells were washed with Milli-Q water and incubated for $24 \mathrm{~h}$ at $37^{\circ} \mathrm{C}$ with freshly made X-gal solution $(0.5 \%$ X-gal, $5 \mathrm{mmol} / \mathrm{L}$ potassium ferricyanide, $5 \mathrm{mmol} / \mathrm{L}$ potassium ferrocyanide, $2 \mathrm{mmol} / \mathrm{L} \mathrm{MgCl}_{2}, 150 \mathrm{mmol} / \mathrm{L} \mathrm{NaCl}, 7 \mathrm{mmol} / \mathrm{L} \mathrm{C}_{6} \mathrm{H}_{8} \mathrm{O}_{7}$, $25 \mathrm{mmol} / \mathrm{L} \mathrm{Na}_{2} \mathrm{HPO}_{4}$ ). Cells were counterstained with pararosaniline (1:25 in Milli-Q water) and imaged using a bright-field microscopy. For each condition, two independent researchers blinded to the experimental plan scored at least 300 cells as negative, low positive or high positive.

\section{Bioenergetics assays}

Mitochondrial respiration was measured as OCR using a XF-24 Extracellular Flux Analyzer (Seahorse Bioscience) as previously described (Milanese et al., 2019). MSCs were seeded at a density of $3 \times 10^{4}$ cells/ 
Table 1. Primer sequences.

\begin{tabular}{|c|c|c|c|c|}
\hline Gene & Forward & Reverse & Probe & Type \\
\hline TWIST1 & $\begin{array}{l}\text { 5'-GTCCGCAGTCTTACGAG- } \\
\text { GAG-3' } \\
\end{array}$ & $\begin{array}{c}\text { 5'-CCAGCTT- } \\
\text { GAGGGTCTGAATC-3' }\end{array}$ & & $\begin{array}{l}\text { SYBR } \\
\text { Green }\end{array}$ \\
\hline RPS27A & $\begin{array}{c}5^{\prime} \text {-TGGCTGTCCTGAAATAT- } \\
\text { TATAAGGT-3' }\end{array}$ & $\begin{array}{l}\text { 5'-CCCCAGCACCA- } \\
\text { CATTCATCA-3' }\end{array}$ & & $\begin{array}{l}\text { SYBR } \\
\text { Green }\end{array}$ \\
\hline IL6 & $\begin{array}{l}\text { 5'ACTCACCTCTTCAGAAC- } \\
\text { GAATTG-3' }\end{array}$ & $\begin{array}{c}\text { 5'-CCATCTTTG- } \\
\text { GAAGGTTCAGGTTG-3' }\end{array}$ & & $\begin{array}{l}\text { SYBR } \\
\text { Green }\end{array}$ \\
\hline CXCL8 (IL8) & $\begin{array}{c}5^{\prime} \text { - TTTTTGAAGAGGGCT- } \\
\text { GAGAATTC-3' }\end{array}$ & $\begin{array}{c}\text { 5'-ATGAAGTGTTGAAG- } \\
\text { TAGATTTGCTTG-3' }\end{array}$ & & $\begin{array}{l}\text { SYBR } \\
\text { Green }\end{array}$ \\
\hline CDKN1A (p21) & $\begin{array}{l}\text { 5'-TGTCCGTCAGGACCCAT- } \\
\text { GC-3' }\end{array}$ & $\begin{array}{l}\text { 5'AAAGTCGAAGTTC- } \\
\text { CATCGCTC-3' }\end{array}$ & & $\begin{array}{l}\text { SYBR } \\
\text { Green }\end{array}$ \\
\hline$C D K N 2 A(p 16)$ & $\begin{array}{c}\text { 5' - GATCCAGGTGGG- } \\
\text { TAGAAGGTC -3' }\end{array}$ & $\begin{array}{l}5^{\prime} \text { - CCCCTGCAAACTTC- } \\
\text { GTCCT - } 3^{\prime}\end{array}$ & & $\begin{array}{l}\text { SYBR } \\
\text { Green }\end{array}$ \\
\hline CCL2 & $\begin{array}{l}\text { 5'-GAGCCAGATGCAAT- } \\
\text { CAATGCC-3' }\end{array}$ & $\begin{array}{c}\text { 5'-TGGAATCCT- } \\
\text { GAACCCACTTCT-3' }\end{array}$ & & $\begin{array}{l}\text { SYBR } \\
\text { Green }\end{array}$ \\
\hline$I L 1 B$ & $\begin{array}{l}\text { 5'-CCTAAACAGATGAAGT- } \\
\text { GCTCCTT-3' }\end{array}$ & $\begin{array}{l}\text { 5'-GTAGTCGGATGCC- } \\
\text { GCCAT-3' }\end{array}$ & & $\begin{array}{l}\text { SYBR } \\
\text { Green }\end{array}$ \\
\hline VEGFA & $\begin{array}{c}5^{\prime} \text {-CTTGCCTTGCTGCTC- } \\
\text { TACC-3' }\end{array}$ & $\begin{array}{c}\text { 5'-CACACAGGATG- } \\
\text { GCTTGAAG-3' }\end{array}$ & & $\begin{array}{l}\text { SYBR } \\
\text { Green }\end{array}$ \\
\hline MMP13 & $\begin{array}{l}\text { 5'-AAGGAGCATGGC- } \\
\text { GACTTCT-3' }\end{array}$ & $\begin{array}{l}\text { 5'-TGGCCCAGGAG- } \\
\text { GAAAAGC-3' }\end{array}$ & $\begin{array}{l}\text { 5'-CCCTCTGGCCTGCTG- } \\
\text { GCTCA-3' }\end{array}$ & TaqMan \\
\hline GAPDH & $\begin{array}{c}\text { 5'-ATGGGGAAGGT- } \\
\text { GAAGGTC G-3' }\end{array}$ & $\begin{array}{l}\text { 5'-TAAAAGCAGCCCTG- } \\
\text { GTGACC-3' }\end{array}$ & $\begin{array}{c}\text { 5'-CGCCCAATACGAC- } \\
\text { CAAATCCGTTGAC-3' }\end{array}$ & TaqMan \\
\hline HPRT1 & $\begin{array}{l}\text { 5'-TTATGGACAGGACT- } \\
\text { GAACGTCTTG-3' }\end{array}$ & $\begin{array}{c}\text { 5'-GCACACAGAGGGC- } \\
\text { TACCATGTG-3' }\end{array}$ & $\begin{array}{l}\text { 5'-AGATGTGATGAAGGA- } \\
\text { GATGGGAG GCCA-3' }\end{array}$ & TaqMan \\
\hline
\end{tabular}

well on Seahorse plates. Optimal cell densities were determined experimentally to ensure a proportional response to FCCP (oxidative phosphorylation uncoupler). $24 \mathrm{~h}$ after cell seeding, the medium was changed to unbuffered DMEM (XF Assay Medium, Agilent Technologies) supplemented with $2 \mathrm{mmol} / \mathrm{L}$ glutamine, $10 \mathrm{mmol} / \mathrm{L}$ glucose and $1 \mathrm{mmol} / \mathrm{L}$ sodium pyruvate and incubated for $1 \mathrm{~h}$ at $37^{\circ} \mathrm{C}$ in the absence of $\mathrm{CO}_{2}$. Three baseline measurements were performed, followed by subsequent measurements after injections of mitochondrial toxins, $1.0 \mu \mathrm{mol} / \mathrm{L}$ oligomycin (ATP-synthase inhibitor), $2.0 \mu \mathrm{mol} / \mathrm{L}$ FCCP and $1 \mu \mathrm{mol} / \mathrm{L}$ antimycin A (complex III inhibitor). Medium and reagents were adjusted to pH 7.4 according to manufacturer's instructions. Non-mitochondrial respiration, basal respiration, proton leak, ATP production, maximal respiration and spare capacity were calculated. The nonmitochondrial respiration was defined as the average OCR values after antimycin A injection. Basal respiration was calculated as the difference between basal respiration and respiration measured after antimycin A injection. Proton leak was calculated as the difference between respiration measured after oligomycin and after antimycin A injections. ATP production was calculated as the difference between baseline respiration and respiration measured after oligomycin injection. Maximal respiration was calculated as the difference between respiration measured after FCCP and after antimycin A injections. Spare capacity was defined as the difference between respiration measured after FCCP injection and baseline respiration.

\section{Data analysis}

Results were statistically analysed using PSAW statistics 20 software (SPSS Inc., Chicago, IL, USA). The normal distribution of the data was determined using the Kolmogorov-Smirnov test. When necessary, data were Log-transformed to meet the normal distribution criteria. An unpaired $t$-test or a linear mixed model was applied; in this model the conditions were considered as fixed parameters and the donors as random factors. $p<0.05$ was considered statistically significant. The grand mean was determined by calculating the mean of the donor means, with 2-6 replicates per donor.

\section{Results}

\section{TWIST1 expression was negatively associated} with cellular senescence in MSCs

To determine whether TWIST1 expression was involved in cellular senescence in human MSCs, its expression was analysed in irradiation-induced senescent MSCs, a commonly used experimental setup to induce senescence. Cellular senescence was induced in MSCs by gamma irradiation (20 Gy) and confirmed by SA- $\beta$-gal staining (Fig. 1a). TWIST1 expression was overall significantly reduced in irradiation-induced senescent MSCs compared to mock-irradiated MSCs; although only $15 \%$ reduction was observed for donor MSC-2 (Fig. $1 \mathbf{b} ; p=0.022)$, indicating that TWIST1 expression was negatively associated with cellular senescence in MSCs. Following this observation, the study 
hypothesis was that high expression of TWIST1 was able to delay the entrance into the senescence state during passaging in vitro. To test this hypothesis, TWIST1 was overexpressed in MSCs by a lentiviralbased approach. Transduction was determined by the percentage of GFP positive cells (> $65 \%$ transduced cells; data not shown) and overexpression confirmed by qPCR analysis (103-fold increase compared to empty vector control; Fig. 1c). Then, control and TWIST1-overexpressing P7 MSCs were serially passaged for $11 \mathrm{~d}$ (up to P10), followed by SA- $\beta$-gal analysis (Fig. 1d), when the cells were divided into negative, low positive or high positive (Fig. 1e). TWIST1-overexpressing MSCs showed an average of $15 \%$ SA- $\beta$-gal low positive cells and $0.4 \%$ SA- $\beta$-gal high positive cells, while empty vector control cells had an average of $52 \%$ SA- $\beta$-gal low positive cells $(p<0.001)$ and $2 \%$ high positive cells $(p=0.052$; Fig. 1f). Overall, these results suggested that TWIST1 expression could inhibit cellular senescence in MSCs.

\section{TWIST1 silencing induced cellular senescence with a specific SASP in MSCs}

To elucidate whether cellular senescence could be induced by TWIST1 modulation, TWIST1 expression was silenced in MSCs (siTWIST1-MSCs) using an siRNA approach. After $24 \mathrm{~h}$, TWIST1 mRNA levels in siTWIST1-MSCs were reduced by $53 \%(p=0.035)$ compared to scramble controls (Fig. 2a), with an increased expression of the cell cycle inhibitor and senescence marker CDKN2A (1.8-fold; $p=0.015$; Fig. 2b) and no difference in CDKN1A (another commonly used senescence marker) expression (Fig. 2c). Additionally, SA- $\beta$-gal analysis revealed no statistically significant difference in the number of cells negative or positive for this senescence marker $24 \mathrm{~h}$ after TWIST1 silencing (Fig. 2d), while following 2 passages, siTWIST1-MSCs become increasingly highly positive for SA- $\beta$-gal (Fig. 3).

After 4 passages, siTWIST1-MSCs showed an average of $64 \%$ knockdown of TWIST1 mRNA levels a
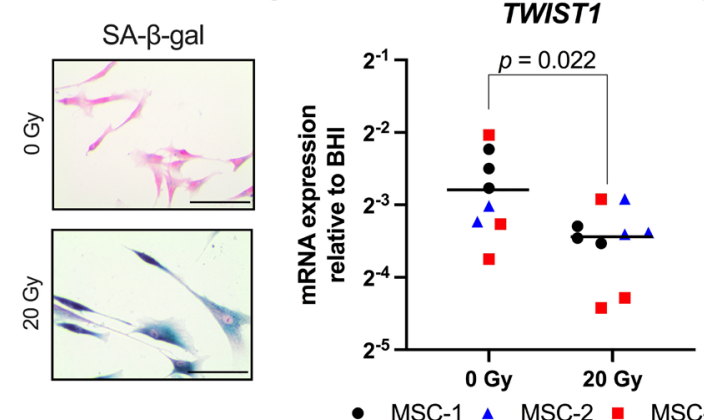

- MSC-1 ^ MSC-2 — MSC-3

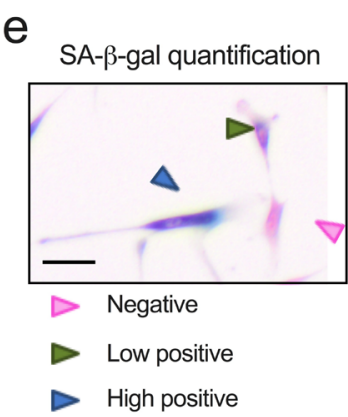

f

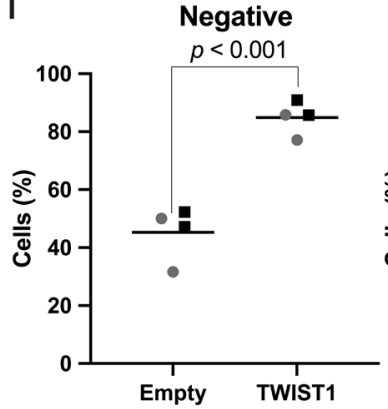

C
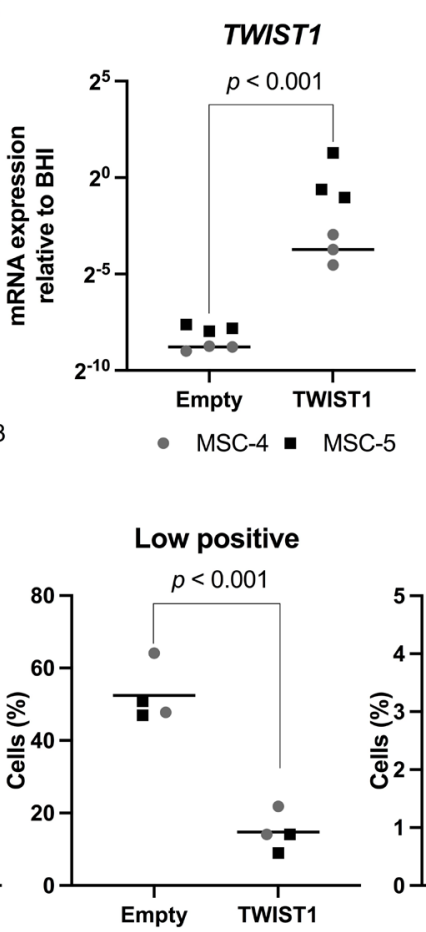

- MSC-4 - MSC-5 d
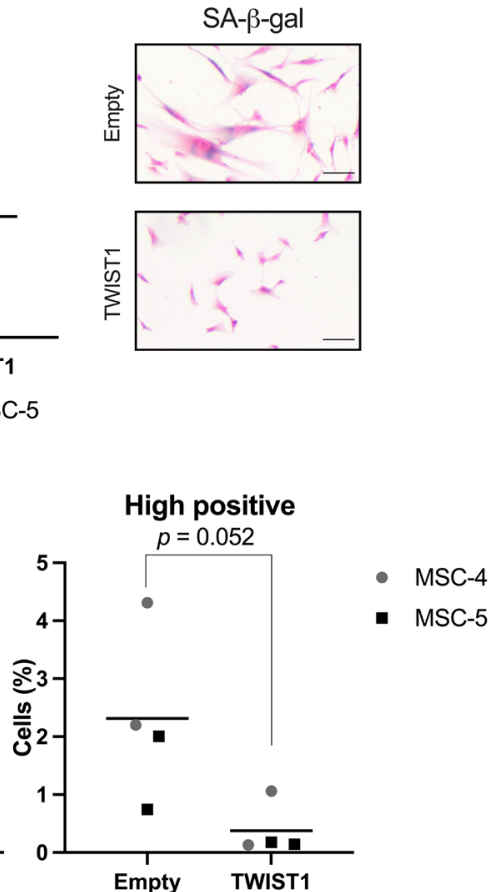

Fig. 1. TWIST1 expression was negatively associated with SA- $\beta$-gal. (a) Representative images of SA- $\beta$-gal staining counterstained with pararosaniline of MSCs $7 \mathrm{~d}$ after gamma irradiation with 0 or $20 \mathrm{~Gy}$. Scale bar: 100 um. (b) TWIST1 mRNA levels of MSCs $7 \mathrm{~d}$ after gamma irradiation with 0 or $20 \mathrm{~Gy}$. Data show individual data points and grand mean with $\mathrm{N}=8(0 \mathrm{~Gy})$ or $\mathrm{N}=9$ (20 Gy), 3 donors with 2-3 replicates per donor, linear mixed model. (c) TWIST1 mRNA levels of MSCs transduced with an empty overexpression lentiviral construct (Empty) or a TWIST1 overexpression lentiviral construct (TWIST1) after $11 \mathrm{~d}$ of expansion. Data show individual data points and grand mean with $\mathrm{N}=6,2$ donors with 3 replicates per donor, linear mixed model. (d) Representative images of SA- $\beta$-gal staining counterstained with pararosaniline of MSCs transduced with an empty overexpression lentiviral control construct (Empty) or a TWIST1 overexpression lentiviral construct (TWIST1) after $11 \mathrm{~d}$ of expansion. Scale bar: $100 \mu \mathrm{m}$. (e) MSCs were categorised as negative for SA- $\beta$-gal staining if no blue staining was detected in the cells (pink arrow). MSCs were categorised as low positive for SA- $\beta$-gal staining if cells showed partial cytoplasmic staining (green arrow). MSCs were categorised as high positive for SA- $\beta$-gal staining if cells showed complete cytoplasmic staining (blue arrow). Scale bar: $50 \mu \mathrm{m}$. (f) SA- $\beta$-gal quantification of MSCs transduced with an empty overexpression lentiviral construct (Empty) or a TWIST1 overexpression lentiviral construct (TWIST1) after $11 \mathrm{~d}$ of expansion. Data show individual data points and grand mean with $\mathrm{N}=4,2$ donors with 2 replicates per donor, linear mixed model. 

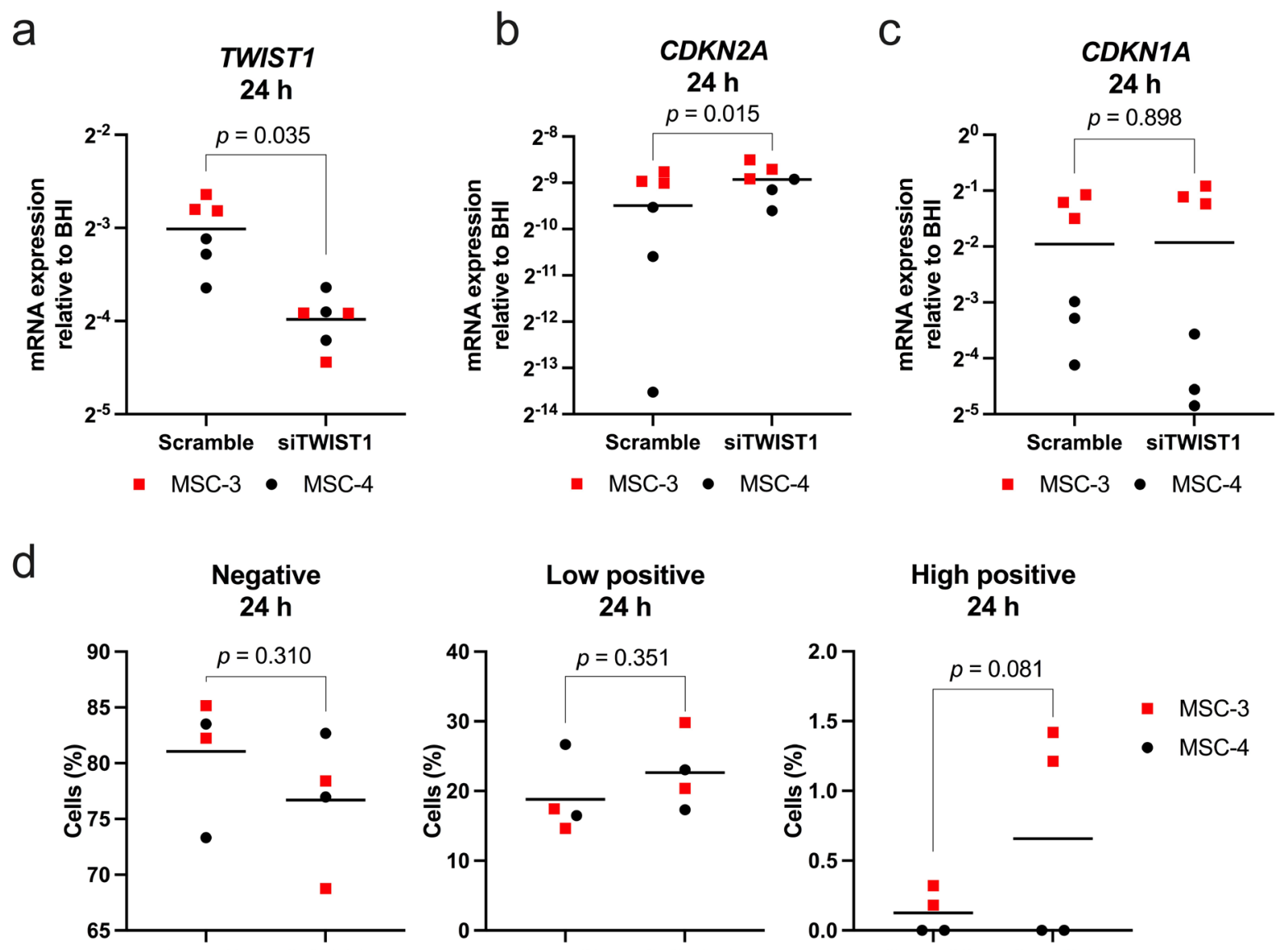

Fig. 2. Senescence markers expression after $24 \mathrm{~h}$ of TWIST1 silencing treatment in MSCs. (a) TWIST1, (b) CDKN2A and (c) CDKN1A mRNA levels in MSCs treated for $24 \mathrm{~h}$ with scramble siRNA (Scramble) or siRNA against TWIST1 (siTWIST1). $\mathrm{N}=6,2$ donors with 3 replicates per donor, linear mixed model. Graphs show individual data points and grand mean. (d) SA- $\beta$-gal quantification of MSCs treated for $24 \mathrm{~h}$ with scramble siRNA (Scramble) or siRNA against TWIST1 (siTWIST1). N = 4, 2 donors with 2 replicates per donor, linear mixed model. Graphs show individual data points and grand mean of percentage of SA- $\beta$-gal negative (left), low positive (middle panel) and high positive (right panel) cells.
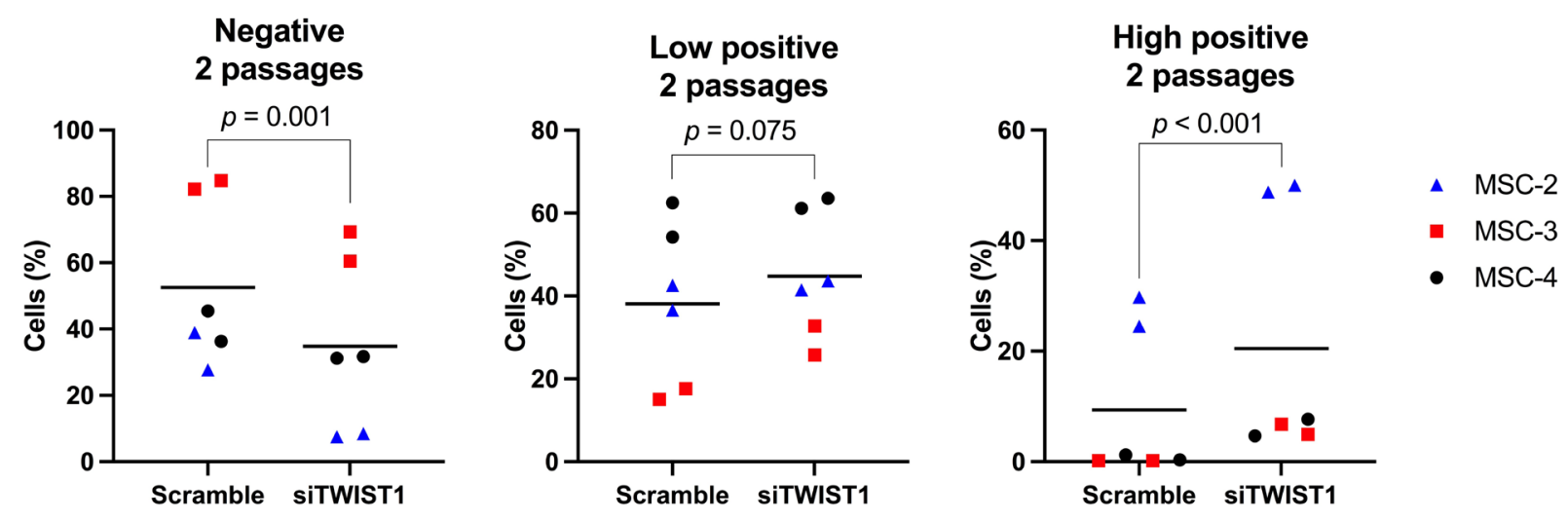

Fig. 3. Senescence markers expression after 2 passages of TWIST1 silencing treatment in MSCs. SA- $\beta$-gal quantification of MSCs treated for 2 passages with scramble siRNA (Scramble) or siRNA against TWIST1 (siTWIST1). $\mathrm{N}=6,3$ donors with 2 replicates per donor, linear mixed model. Graphs show individual data points and grand mean of percentage of SA- $\beta$-gal negative (left), low positive (middle panel) and high positive (right panel) cells. 
a

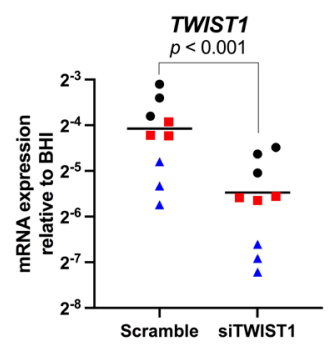

- MSC-2 - MSC-3 • MSC-4
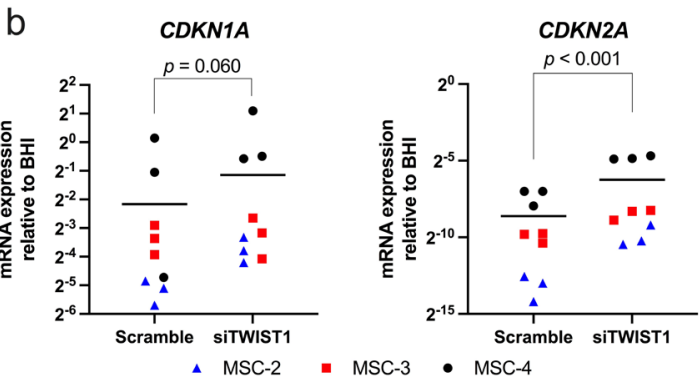

C
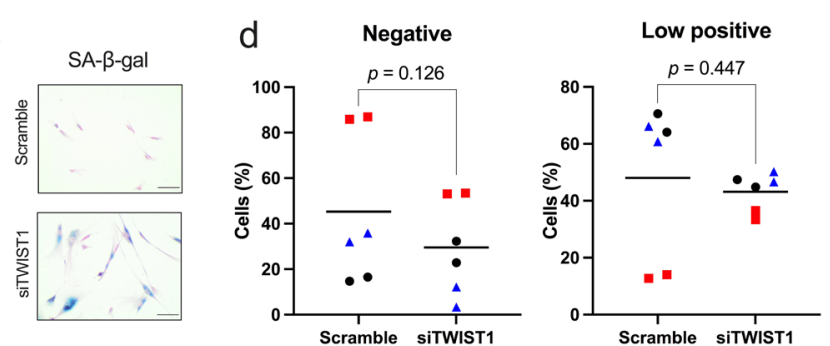

High positive

e
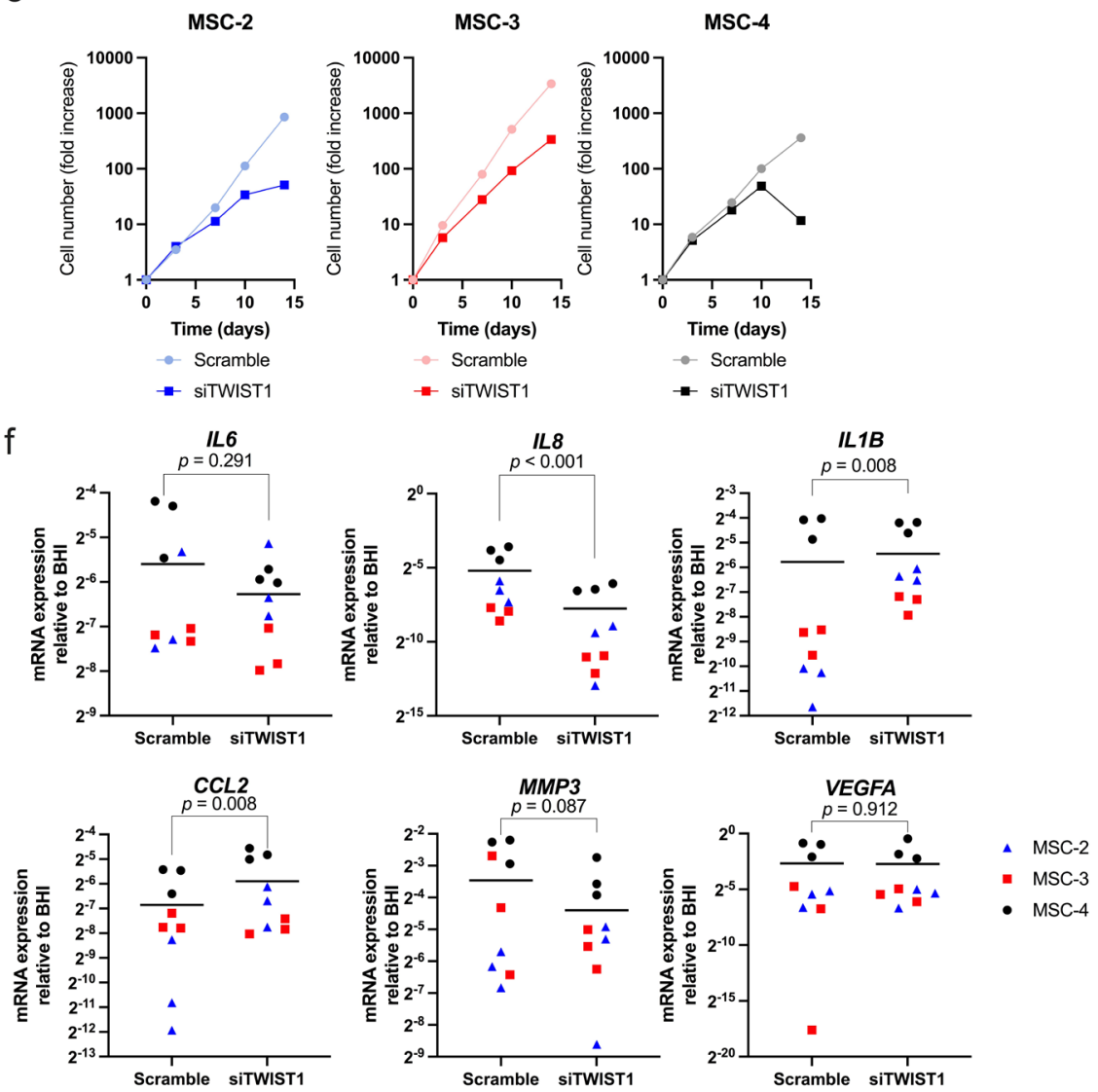

Fig. 4. TWIST1 silencing induced cellular senescence in MSCs with a specific SASP mRNA expression profile. (a) TWIST1 mRNA levels in MSCs treated for 4 passages with scramble siRNA (Scramble) or siRNA against TWIST1 (siTWIST1). $\mathrm{N}=9,3$ donors with 3 replicates per donor, linear mixed model. (b) CDKN2A and CDKN1A mRNA levels in MSCs treated for 4 passages with scramble siRNA (Scramble) or siRNA against TWIST1 (siTWIST1). $\mathrm{N}=9,3$ donors with 3 replicates per donor, linear mixed model. (c) Representative images of SA- $\beta$-gal staining counter stained with pararosaniline of MSCs treated for 4 passages with scramble siRNA (Scramble) or siRNA against TWIST1 (siTWIST1). Scale bar: $100 \mu \mathrm{m}$. (d) SA- $\beta$-gal quantification of MSCs treated for 4 passages with scramble siRNA (Scramble) or siRNA against TWIST1 (siTWIST1). $\mathrm{N}=6,3$ donors with 2 replicates per donor, linear mixed model. Graphs show individual data points and grand mean of percentage of SA- $\beta$-gal negative (left), low positive (middle panel) and high positive (right panel) cells. (e) Cell number data during expansion of MSCs treated with scramble siRNA (Scramble) or siRNA against TWIST1 (siTWIST1) at day $0,3,7,10$ and 14 of treatment, $\mathrm{N}=3$ donors. (f) IL6, IL8, IL1B, CCL2, MMP3 and VEGFA mRNA levels in MSCs treated for 4 passages with scramble siRNA (Scramble) or siRNA against TWIST1 (siTWIST1). $\mathrm{N}=9,3$ donors with 3 replicates per donor, linear mixed model. Graphs show individual data points and grand mean. 
( $p<0.001$; Fig. 4a) and TWIST1 silencing increased the expression of CDKN2A (6.5-fold, $p<0.001)$ and CDKN1A (2.1-fold, $p=0.060$; Fig. 4b). In addition, after 4 passages, TWIST1 silencing increased SA- $\beta$ gal activity in MSCs (Fig. 4c,d) and decreased cell expansion rate (Fig. 4e), overall indicating that TWIST1 knockdown induced senescence-associated growth arrest. Since the SASP can drive chronic inflammation and thereby contribute to age-related diseases such as osteoarthritis and cancer (as reviewed by Loeser $e t$ al., 2016; Zhu et al., 2014), the expression of the SASPrelated genes IL6, IL1B, MMP3, IL8, CCL2 and VEGFA was determined in siTWIST1-MSCs. Interestingly, siTWIST1-MSCs expressed higher levels of CCL2 and ILIB compared to control condition, although the effect was donor dependent (3.3-fold $p=0.008$, 7.4-fold $p=0.008$, respectively; Fig. 4f). Moreover, the expression of IL6, MMP3 and VEGFA was not significantly affected and IL8 expression was even significantly decreased $(p=0.291, p=0.077, p=0.087$, $p=0.912, p<0.001$, respectively; Fig. 4 f). These results indicated that senescence was induced in MSCs by TWIST1 knockdown but generating a non-classical SASP profile.

\section{TWIST1 silencing altered MSC bioenergetics}

Since the expression of the SASP is associated with the metabolic state of the cell (Dörr et al., 2013; Lunyak et al., 2017; Wiley et al., 2016), the bioenergetic profile in siTWIST1-MSCs was monitored using a Seahorse XF-24 Extracellular Flux Analyzer. The OCR reflecting cellular respiration was measured

\section{a Mitochondrial stress test}

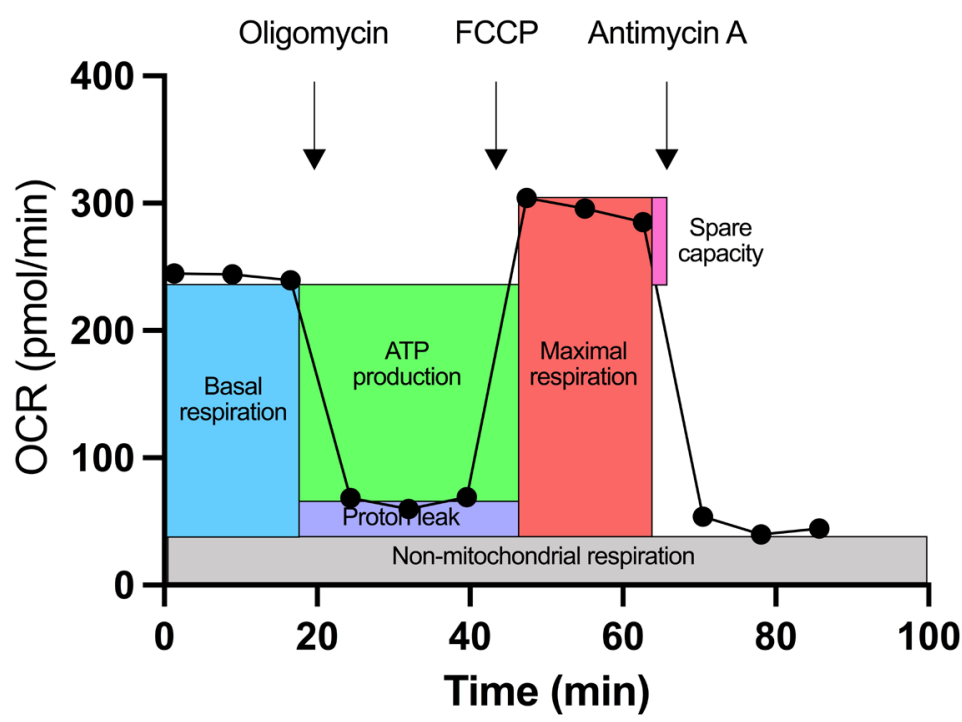

b
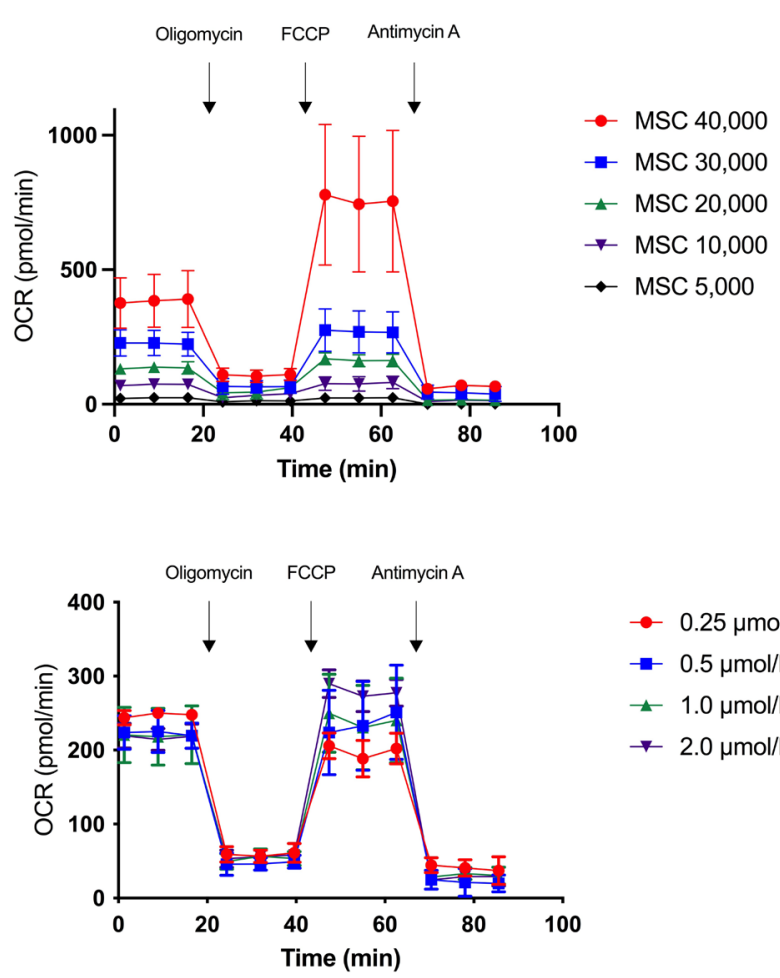

- $0.25 \mu \mathrm{mol} / \mathrm{L}$ FCCP

- $0.5 \mu \mathrm{mol} / \mathrm{L} \mathrm{FCCP}$

$\star 1.0 \mu \mathrm{mol} / \mathrm{L} \mathrm{FCCP}$

$\rightarrow 2.0 \mu \mathrm{mol} / \mathrm{L} \mathrm{FCCP}$
Fig. 5. Optimisation of the cell number and FCCP concentration for the mitochondrial stress test using Seahorse technology. (a) The OCR in MSCs was measured using Seahorse technology followed by subsequent measurements after injection of mitochondrial toxins: oligomycin, FCCP and antimycin A. This assay used the built-in injection ports on Seahorse XF sensor cartridges to add the mitochondrial toxins (modulators of respiration) into cell wells during the assay to reveal the key parameters of mitochondrial function. Specifically, using the mitochondrial stress test basal OCR, ATP production, maximum OCR, spare capacity, non-mitochondrial respiration and proton leak were determined. (b) Mitochondrial stress test with different MSC densities per well (5,000, 10,000, 20,000, 30,000 and 40,000) using $1.0 \mu \mathrm{mol} / \mathrm{L} \mathrm{FCCP.}$ (c) Mitochondrial stress test with 30,000 MSCs per well using different concentrations of FCCP $(0.25,0.5$, 1.0 and $2.0 \mu \mathrm{mol} / \mathrm{L}) . \mathrm{N}=5-7,1$ donor with 5-7 replicates per donor. Graphs represent mean with SD. A detailed explanation of the mitochondrial stress test is provided in Materials and Methods. 
followed by subsequent measurement after injection of mitochondrial toxins: oligomycin, FCCP and antimycin A (see Materials and Methods and Fig. 5a). First, optimal cell density (30,000 cells/well; Fig. 5b) and the ideal concentration of FCCP $(2.0 \mu \mathrm{mol} / \mathrm{L}$; Fig. $5 c)$ to detect OCR in human MSCs were identified. Then, a significant increase in basal respiration levels was observed in siTWIST1-MSCs compared to scramble controls ( $p=0.011$; Fig. 6a-c). In addition, siTWIST1-MSCs showed higher values for maximum
OCR, proton leak, ATP production and spare respiratory capacity compared to scramble control cells $(p=0.001, p=0.006, p=0.002$ and $p=0.001$, respectively; Fig. $6 \mathbf{d}-\mathbf{g})$. No differences in nonmitochondrial respiration were observed between scramble control and siTWIST1-MSCs $(p=0.251$; Fig. 6h). Overall, these data indicated that TWIST1 silencing induced changes in the MSC mitochondrial function, although in one of the two donors (MSC-6) the effect of the silencing was less pronounced.

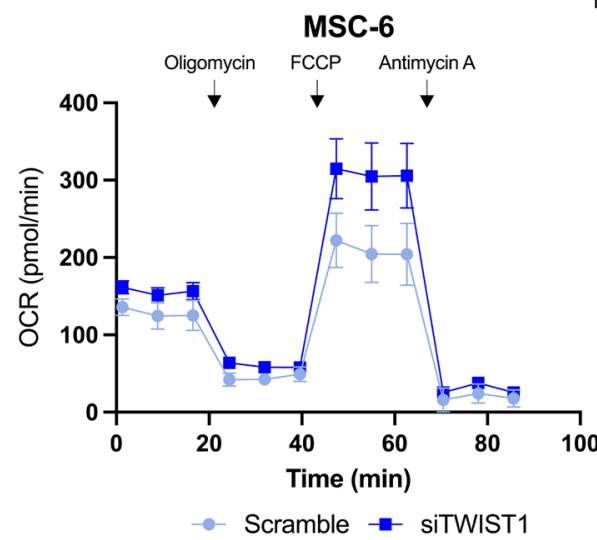

C

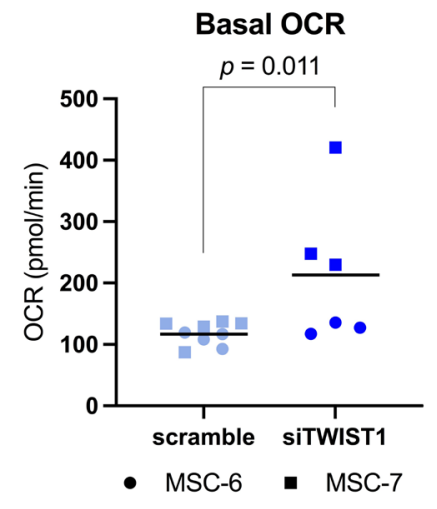

f

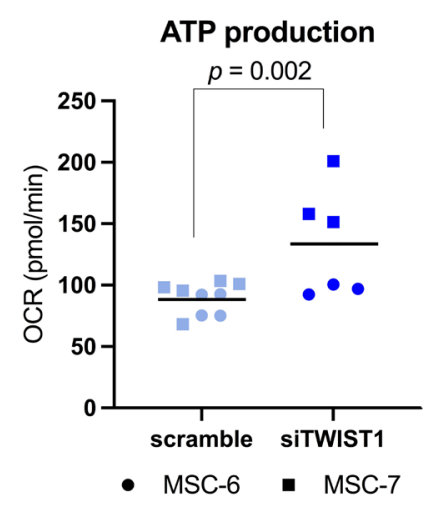

d

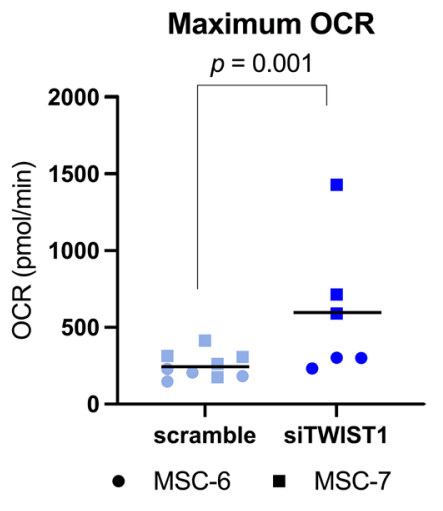

g

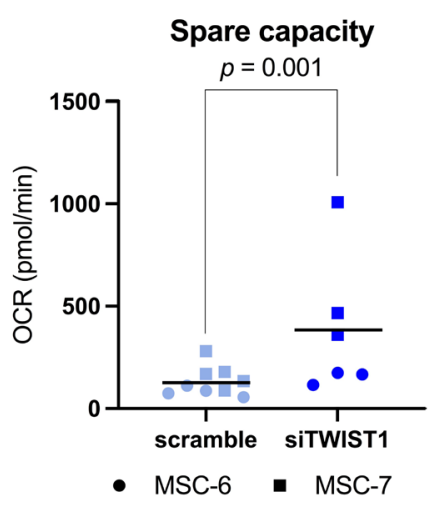

b

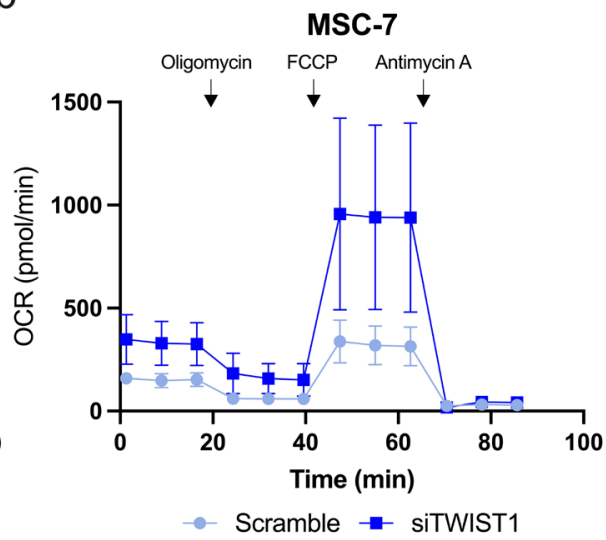

e

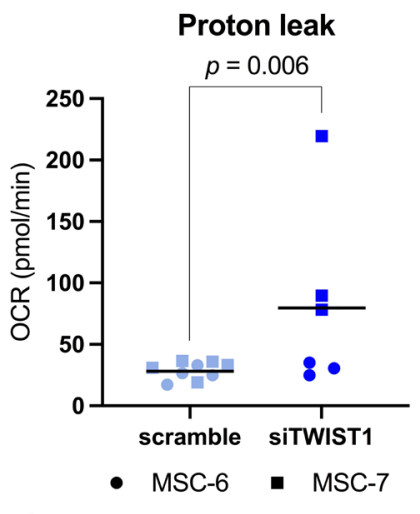

$\mathrm{h}$

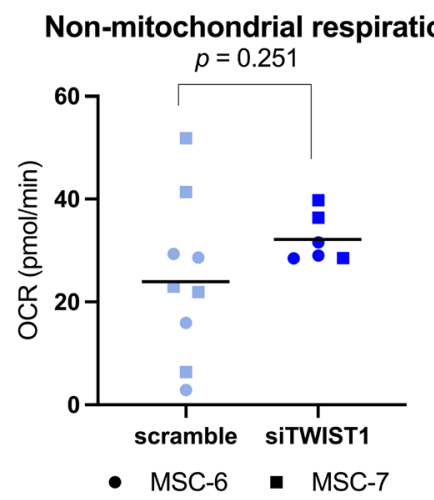

Fig. 6. Increased OCR in TWIST1-silenced MSCs. (a-b) Graphs show the OCR in MSCs treated with a scramble or TWIST1 siRNA at basal level and after addition of oligomycin, FCCP and antimycin A in two different donors, (a) MSC-6 and (b) MSC-7. Values represent mean with SD, N=3-5 replicates per donor. (c-h) Graphs show calculated values for (c) basal OCR, (d) maximum OCR, (e) proton leak, (f) ATP production, (g) spare capacity and (h) non-mitochondrial respiration in MSCs treated with scramble or TWIST1 siRNA. $\mathrm{N}=6-9,2$ donors with 3-5 replicates per donor, linear mixed model. Graphs show individual data points and grand mean. 
SASP expression was different between TWIST1silencing-induced senescent MSCs and irradiationinduced senescent MSCs (Fig. 4). Therefore, possible differences in their metabolic profile were investigated. As a measure of mitochondrial respiration, the ORC value of siTWIST1-MSCs was compared to irradiation-induced senescent MSCs. Similarly to siTWIST1-MSCs, irradiation-induced senescent MSCs showed higher values for basal OCR, maximum OCR, proton leak and ATP production compared to non-irradiated control cells $(p<0.001$, $p=0.046, p=0.016$ and $p<0.001$, respectively; Fig. 7a-f). Moreover, no overall differences were observed in spare respiratory capacity - due to an opposite response of the two donors tested - and in non-mitochondrial respiration compared to controls $(p=0.256$; Fig. $7 \mathbf{g}, \mathbf{h})$. These data suggested that both siTWIST1-MSCs and irradiation-induced senescent MSCs had a similar increased OCR to non-senescent MSCs.

As a measure of glycolytic flux, the ECAR in siTWIST1-MSCs and irradiated MSCs was analysed. Irradiated MSCs had a higher ECAR compared to control MSCs (Fig. 8), while no significant differences in ECAR were observed between scramble control cells and siTWIST1-MSCs (Fig. 9), indicating that TWIST1 silencing did not alter the glycolytic flux in MSCs. This suggested that, in contrast to irradiationinduced senescent MSCs, the glycolytic capacity was unaltered in siTWIST1-MSCs compared to untreated controls. a

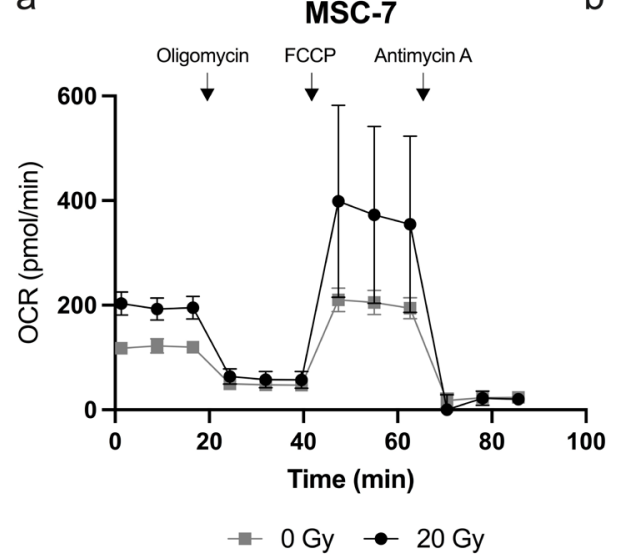

C

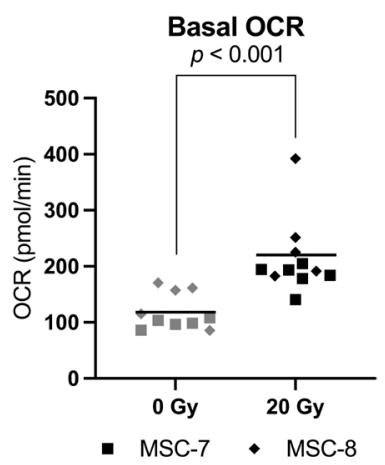

f

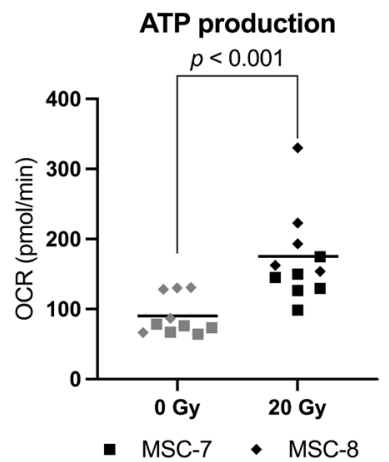

d

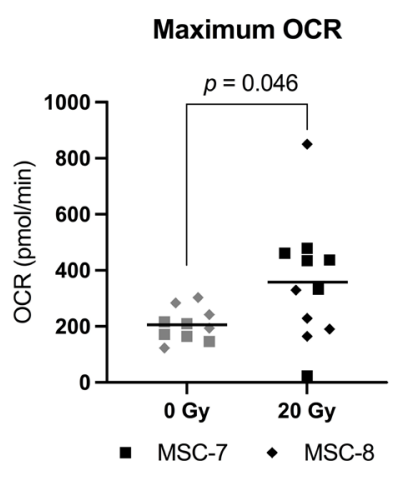

g

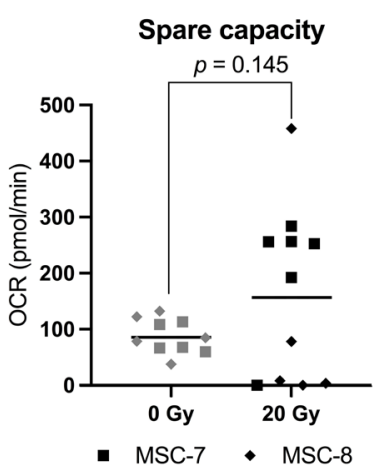

MSC-8

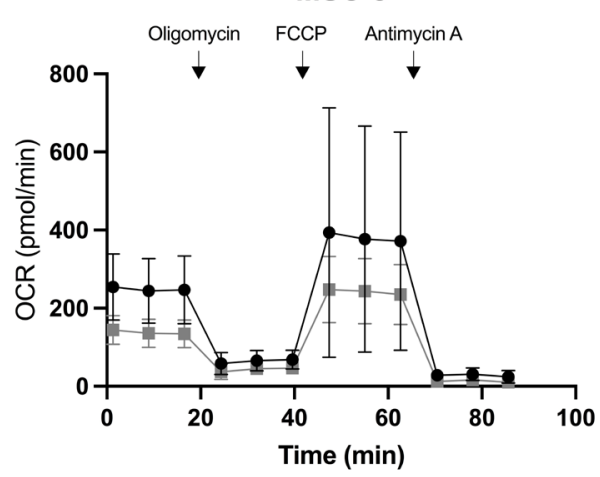

$-0 \mathrm{~Gy} \rightarrow 20 \mathrm{~Gy}$

e

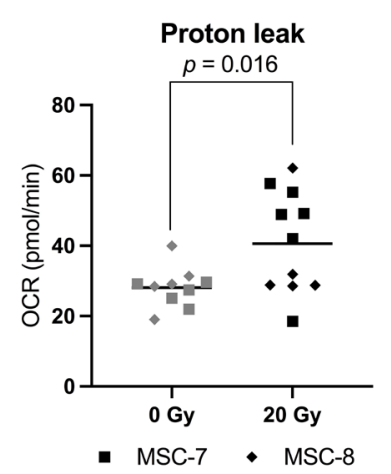

$\mathrm{h}$

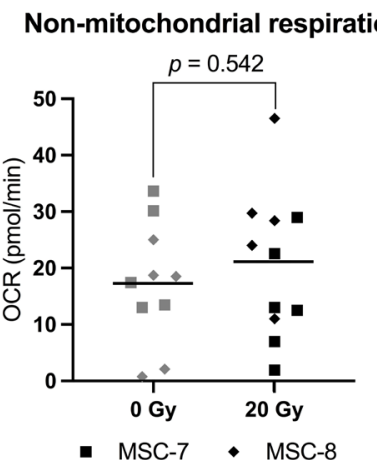

Fig. 7. Increased OCR in irradiated MSCs. (a-b) Graphs show the OCR in MSCs irradiated with 0 or 20 Gy after addition of oligomycin, FCCP and antimycin A in two different donors, (a) MSC-7 and (b) MSC-8. Values represent mean with SD, N =5-6 replicates per donor. (c-h) Graphs show calculated values for (c) basal OCR, (d) maximum OCR, (e) proton leak, (f) ATP production, (g) spare capacity and (h) non-mitochondrial respiration in MSCs irradiated with 0 or 20 Gy. $N=11,2$ donors with 5-6 replicates per donor, linear mixed model. Graphs show individual data points and grand mean. 


\section{Discussion}

TWIST1 expression has been associated with rapid cell growth and a high proliferation capacity of MSCs (Boregowda et al., 2016; Isenmann et al., 2009; Voskamp et al., 2020). High TWIST1 expression levels in MSC are associated with enhanced differentiation capacity, especially towards the adipogenic and chondrogenic lineage (Cleary et al., 2017; Narcisi et al., 2015). The present study showed that enforced TWIST1 expression suppressed MSC senescence and increased their proliferation capacity. On the other hand, the study demonstrated that TWIST1 silencing in MSCs induced cellular senescence with a non-classical SASP profile, lacking IL6 and IL8 expression. The expression of SASP is regulated by mitochondria and TWIST1 plays an essential role in the mitochondrial metabolism of cancer cells and adipocytes, since downregulation of TWIST1 promotes mitochondrial dysfunction (Lu et al., 2018; Seo et al., 2014). Mitochondrial dysfunction can induce cellular senescence with a different SASP profile, referred to as MiDAS (Wiley et al., 2016). Cells with MiDAS have a SASP expression profile similar a

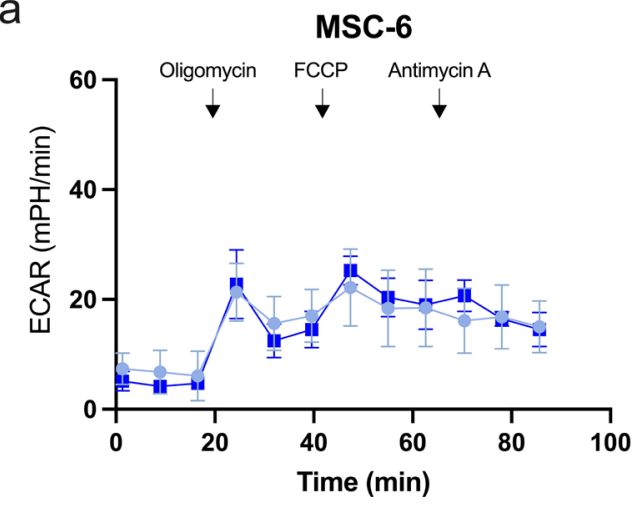

b

- Scramble $\rightarrow$ siTWIST1

MSC-7

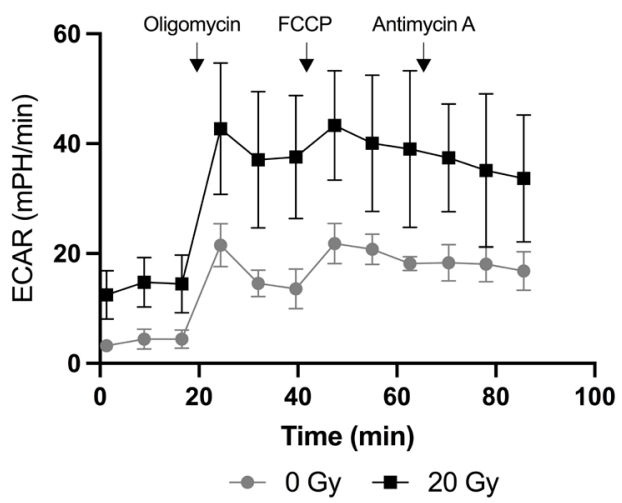

C

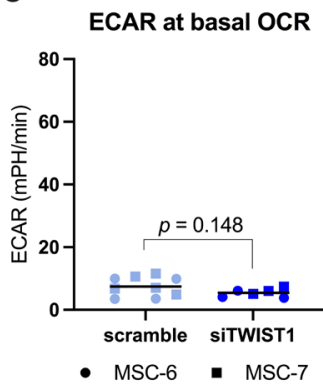

d

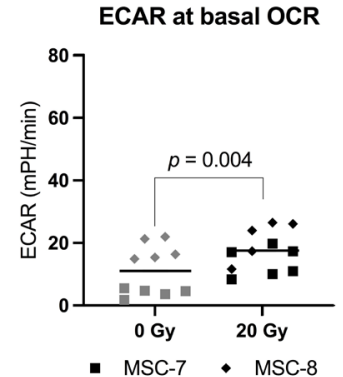

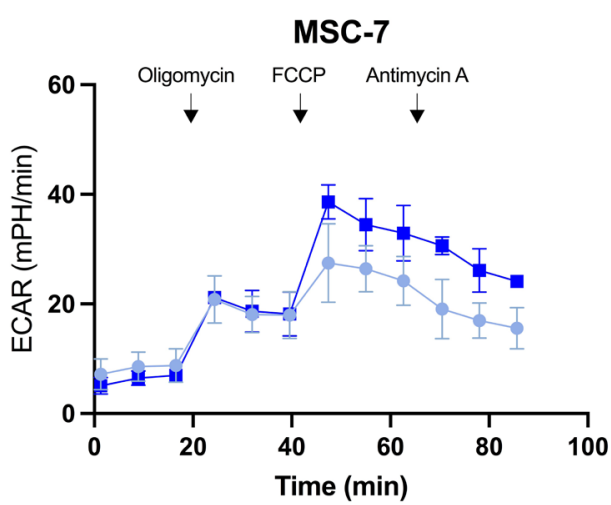

$\rightarrow$ Scramble $\rightarrow$ siTWIST1

MSC-8

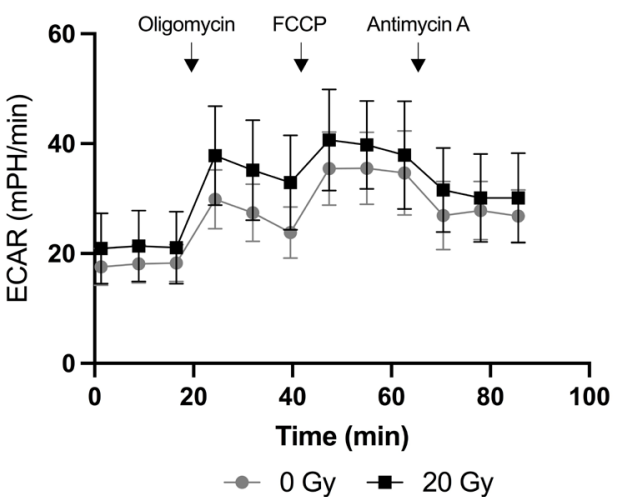

e ECAR at maximum OCR f

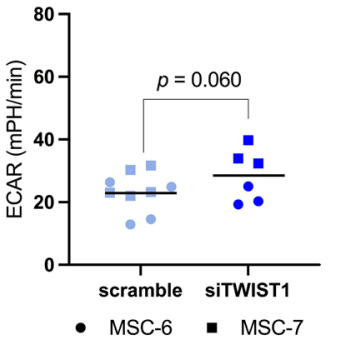

Fig. 8. TWIST1 silencing did not increases ECAR in MSCs. (a) Graphs show the ECAR in MSCs treated with a scramble or TWIST1 siRNA at basal level and after addition of oligomycin, FCCP and antimycin A in two different donors, MSC-6 and MSC-7. Values represent mean with SD, N = 3-5 replicates per donor. (b) Graphs show the ECAR in MSCs irradiated with 0 or 20 Gy after addition of oligomycin, FCCP and antimycin A in two different donors, MSC-7 and MSC-8. Values represent mean with SD, N = 5-6 replicates per donor. (c,e) Graphs show ECAR values for (c) basal OCR and (e) maximum OCR in MSCs treated with scramble or TWIST1 siRNA. $\mathrm{N}=8,2$ donors with 3-5 replicates per donor, linear mixed model. Graphs show individual data points and grand mean. (d,f) Graphs show ECAR values for (d) basal OCR and (f) maximum OCR in MSCs irradiated with 0 or $20 \mathrm{~Gy} . \mathrm{N}=11,2$ donors with 5-6 replicates per donor, linear mixed model. Graphs show individual data points and grand mean. 
to siTWIST1-MSCs (Wiley et al., 2016), suggesting that TWIST1 silencing might induce cellular senescence in MSCs through mitochondrial dysfunction.

Both mitochondrial dysfunction and cellular senescence are hallmarks of ageing and senescent cells have an altered mitochondrial biogenesis. The present study showed that both TWIST1-silencinginduced and irradiation-induced senescent MSCs had an increased proton leak, indicating that senescent MSCs have dysfunctional mitochondria. Dysfunctional mitochondria can trigger cellular senescence (Wiley et al., 2016) and removal of mitochondria in senescent cells has been shown to reduce the senescence phenotype (CorreiaMelo et al., 2016), suggesting that dysfunctional mitochondria are essential for the senescence phenotype. Dysfunctional mitochondria are associated with altered mitochondrial bioenergetics and increased mitochondrial mass. Indeed, senescent MSCs had an increased OCR, which could be the results of either increased mitochondrial respiration or increased mitochondrial mass. An increase in mitochondrial mass has been reported before for senescent fibroblasts (Correia-Melo et al., 2016; Lee et al., 2002). In addition, dysfunctional mitochondria produce enhanced levels of reactive oxygen species, which stimulate the induction of cellular senescence (Brookes, 2005; Nelson et al., 2018). Dysfunctional mitochondria can modulate the SASP through complex mechanisms (Chapman et al., 2019). Despite the difference in the SASP, both TWIST1silencing-induced and irradiation-induced senescent MSCs showed a similar increase in mitochondrial respiration.

In addition to mitochondrial respiration, glycolysis plays an important role in MSC energy metabolism (Pattappa et al., 2011). Cellular senescence has been associated with an increased glycolytic capacity after in vitro expansion in fibroblasts (Bittles and Harper, 1984). The present study showed that irradiationinduced senescent MSCs had an increased ECAR compared to control MSCs, confirming earlier published data in fibroblasts (James et al., 2015). However, TWIST1-silencing-induced senescent MSCs did not show significant differences in ECAR compared to control MSCs. These data suggested that the glycolytic capacity was unaltered in siTWIST1MSCs and showed that senescent MSCs could have a different bioenergetic profile depending on the inducer of senescence.

It is of note that SASP factors are not only known to play a role in senescence but they are also involved in development and tissue repair (Rhinn et al., 2019). For example, cells transiently exposed to the SASP have enhanced expression of classical stem cell markers and regenerative capacity, while prolonged exposure induces cell-intrinsic senescence arrest (Ritschka et al., 2017). This indicates that these factors can play different roles depending on the exposition time of the cell to the stimuli. However, very little is known about how different kinds of senescent cells and SASP contribute to the induction of senescence or tissue regeneration, for example by transiently or permanently changing the metabolic state of the cells. A better understanding of these processes could contribute to develop new tools that may be used in regenerative medicine.

In summary, the present study provided novel insights in the function of TWIST1 in regulating cellular senescence in MSCs, suggesting that reduction in TWIST1 expression might drive the ageing phenotypes of MSCs. Furthermore, the phenotype of these siTWIST1-induced senescent MSCs differs from irradiation-induced senescent cells regarding their expression of the SASP and their bioenergetics, highlighting that senescent MSCs can manifest in different ways.

\section{Acknowledgements}

The authors would like to thank Andrea Lolli for advice on the TWIST1 silencing protocol, Eric Farrell and Janneke Witte-Bouma for access to their source of MSCs, Nicole Kops and Arielle Molina Rakos for technical assistance with the senescence-associated $\beta$-galactosidase staining and quantification, Marius Wernig's laboratory (Stanford School of Medicine, Sandford, CA, USA) for providing the GFP overexpression construct and the lentiviral packaging constructs, the FACS sorting facility at the Erasmus MC for support with the BD LSRFortessa $^{\mathrm{TM}}$ Cell Analyzer.

This research was financially supported by the Dutch Arthritis Society (ReumaNederland; 16-1-201) and by a TTW Perspectief grant from NWO (William Hunter Revisited; P15-23). This study is part of the Medical Delta RegMed4D program and the Erasmus Postgraduate School Molecular Medicine.

The authors have no conflict of interest to declare.

\section{Author Contribution}

Planning: Chantal Voskamp, Pier G. Mastroberardino, Gerjo J.V.M. van Osch, Roberto Narcisi. Data collection: Chantal Voskamp, Laura Anderson, Wendy J.L.M. Koevoet, Sander Barnhoorn. Data analysis: all authors. Manuscript preparation and editing: Chantal Voskamp, Pier G. Mastroberardino, Gerjo J.V.M. van Osch, Roberto Narcisi. Final approval of the submission: all authors.

All datasets generated for this study are available upon request to the corresponding author.

\section{References}

Bittles AH, Harper N (1984) Increased glycolysis in ageing cultured human diploid fibroblasts. Biosci Rep 4: 751-756. 
Boregowda SV, Krishnappa V, Haga CL, Ortiz LA, Phinney DG (2016) A clinical indications prediction scale based on TWIST1 for human mesenchymal stem cells. EBioMedicine 4: 62-73.

Brookes PS (2005) Mitochondrial H(+) leak and ROS generation: an odd couple. Free Radic Biol Med 38: 12-23.

Cakouros D, Isenmann S, Cooper L, Zannettino A, Anderson P, Glackin C, Gronthos S (2012) Twist-1 induces Ezh2 recruitment regulating histone methylation along the Ink4A/Arf locus in mesenchymal stem cells. Mol Cell Biol 32: 1433-1441.

Chapman J, Fielder E, Passos JF (2019) Mitochondrial dysfunction and cell senescence: deciphering a complex relationship. FEBS Lett 593: 1566-1579.

Cheng H, Qiu L, Ma J, Zhang H, Cheng M, Li W, Zhao X, Liu K (2011) Replicative senescence of human bone marrow and umbilical cord derived mesenchymal stem cells and their differentiation to adipocytes and osteoblasts. Mol Biol Rep 38: 51615168.

Cleary MA, Narcisi R, Albiero A, Jenner F, de Kroon LMG, Koevoet W, Brama PAJ, van Osch G (2017) Dynamic regulation of TWIST1 expression during chondrogenic differentiation of human bone marrow-derived mesenchymal stem cells. Stem Cells Dev 26: 751-761.

Correia-Melo C, Marques FD, Anderson R, Hewitt G, Hewitt R, Cole J, Carroll BM, Miwa S, Birch J, Merz A, Rushton MD, Charles M, Jurk D, Tait SW, Czapiewski R, Greaves L, Nelson G, Bohlooly YM, Rodriguez-Cuenca S, Vidal-Puig A, Mann D, Saretzki G, Quarato G, Green DR, Adams PD, von Zglinicki T, Korolchuk VI, Passos JF (2016) Mitochondria are required for pro-ageing features of the senescent phenotype. Embo J 35: 724-742.

Dörr JR, Yu Y, Milanovic M, Beuster G, Zasada C, Däbritz JH, Lisec J, Lenze D, Gerhardt A, Schleicher K, Kratzat S, Purfürst B, Walenta S, Mueller-Klieser W, Gräler M, Hummel M, Keller U, Buck AK, Dörken B, Willmitzer L, Reimann M, Kempa S, Lee S, Schmitt CA (2013) Synthetic lethal metabolic targeting of cellular senescence in cancer therapy. Nature 501: 421-425.

Erices A, Conget P, Minguell JJ (2000) Mesenchymal progenitor cells in human umbilical cord blood. Br J Haematol 109: 235-242.

Halvorsen YC, Wilkison WO, Gimble JM (2000) Adipose-derived stromal cells - their utility and potential in bone formation. Int J Obes Relat Metab Disord 24 Suppl 4: S41-44.

Haynesworth SE, Goshima J, Goldberg VM, Caplan AI (1992) Characterization of cells with osteogenic potential from human marrow. Bone 13: 81-88.

Hochane M, Trichet V, Pecqueur C, Avril P, Oliver L, Denis J, Brion R, Amiaud J, Pineau A, Naveilhan P, Heymann D, Vallette FM, Olivier C (2017) Lowdose pesticide mixture induces senescence in normal mesenchymal stem cells (MSC) and promotes tumorigenic phenotype in premalignant MSC. Stem Cells 35: 800-811.

Isenmann S, Arthur A, Zannettino AC, Turner JL, Shi S, Glackin CA, Gronthos S (2009) TWIST family of basic helix-loop-helix transcription factors mediate human mesenchymal stem cell growth and commitment. Stem Cells 27: 2457-2468.

James EL, Michalek RD, Pitiyage GN, de Castro AM, Vignola KS, Jones J, Mohney RP, Karoly ED, Prime SS, Parkinson EK (2015) Senescent human fibroblasts show increased glycolysis and redox homeostasis with extracellular metabolomes that overlap with those of irreparable DNA damage, aging, and disease. J Proteome Res 14: 1854-1871.

Knuth CA, Kiernan CH, Palomares Cabeza V, Lehmann J, Witte-Bouma J, Ten Berge D, Brama PA, Wolvius EB, Strabbing EM, Koudstaal MJ, Narcisi R, Farrell E (2018) Isolating pediatric mesenchymal stem cells with enhanced expansion and differentiation capabilities. Tissue Eng Part C Methods 24: 313-321.

Kumari R, Jat P (2021) Mechanisms of cellular senescence: cell cycle arrest and senescence associated secretory phenotype. Front Cell Dev Biol 9: 645593.

Lee HC, Yin PH, Chi CW, Wei YH (2002) Increase in mitochondrial mass in human fibroblasts under oxidative stress and during replicative cell senescence. J Biomed Sci 9: 517-526.

Li Y, Wu Q, Wang Y, Li L, Bu H, Bao J (2017) Senescence of mesenchymal stem cells (Review). Int J Mol Med 39: 775-782.

Li Y, Xu X, Wang L, Liu G, Li Y, Wu X, Jing Y, Li H, Wang G (2015) Senescent mesenchymal stem cells promote colorectal cancer cells growth via galectin-3 expression. Cell Biosci 5: 21. DOI: 10.1186/s13578-0150012-3

Loeser RF, Collins JA, Diekman BO (2016) Ageing and the pathogenesis of osteoarthritis. Nat Rev Rheumatol 12: 412-420.

Lu S, Wang H, Ren R, Shi X, Zhang Y, Ma W (2018) Reduced expression of Twist 1 is protective against insulin resistance of adipocytes and involves mitochondrial dysfunction. Sci Rep 8: 12590. DOI: 10.1038/s41598-018-30820-z.

Lunyak VV, Amaro-Ortiz A, Gaur M (2017) Mesenchymal stem cells secretory responses: senescence messaging secretome and immunomodulation perspective. Front Genet 8: 220. DOI: 10.3389/fgene.2017.00220.

Milanese C, Bombardieri CR, Sepe S, Barnhoorn S, Payán-Goméz C, Caruso D, Audano M, Pedretti S, Vermeij WP, Brandt RMC, Gyenis A, Wamelink MM, de Wit AS, Janssens RC, Leen R, van Kuilenburg ABP, Mitro N, Hoeijmakers JHJ, Mastroberardino PG (2019) DNA damage and transcription stress cause ATP-mediated redesign of metabolism and potentiation of anti-oxidant buffering. Nat Commun 10: 4887.

Narcisi R, Cleary MA, Brama PA, Hoogduijn MJ, Tüysüz N, ten Berge D, van Osch GJ (2015) Long-term expansion, enhanced chondrogenic potential, and suppression of endochondral ossification of adult 
human MSCs via WNT signaling modulation. Stem Cell Reports 4: 459-472.

Nelson G, Kucheryavenko O, Wordsworth J, von Zglinicki T (2018) The senescent bystander effect is caused by ROS-activated NF- $\kappa \mathrm{B}$ signalling. Mech Ageing Dev 170: 30-36.

Pattappa G, Heywood HK, de Bruijn JD, Lee DA (2011) The metabolism of human mesenchymal stem cells during proliferation and differentiation. J Cell Physiol 226: 2562-2570.

Pfaffl MW, Tichopad A, Prgomet C, Neuvians TP (2004) Determination of stable housekeeping genes, differentially regulated target genes and sample integrity: BestKeeper-Excel-based tool using pairwise correlations. Biotechnol Lett 26: 509-515.

Pittenger MF, Mackay AM, Beck SC, Jaiswal RK, Douglas R, Mosca JD, Moorman MA, Simonetti DW, Craig S, Marshak DR (1999) Multilineage potential of adult human mesenchymal stem cells. Science 284 : 143-147.

Rhinn M, Ritschka B, Keyes WM (2019) Cellular senescence in development, regeneration and disease. Development 146.

Ritschka B, Storer M, Mas A, Heinzmann F, Ortells MC, Morton JP, Sansom OJ, Zender L, Keyes WM (2017) The senescence-associated secretory phenotype induces cellular plasticity and tissue regeneration. Genes Dev 31: 172-183.

Romanov YA, Svintsitskaya VA, Smirnov VN (2003) Searching for alternative sources of postnatal human mesenchymal stem cells: candidate MSC-like cells from umbilical cord. Stem Cells 21: 105-110.

Seo SK, Kim JH, Choi HN, Choe TB, Hong SI, Yi JY, Hwang SG, Lee HG, Lee YH, Park IC (2014) Knockdown of TWIST1 enhances arsenic trioxideand ionizing radiation-induced cell death in lung cancer cells by promoting mitochondrial dysfunction. Biochem Biophys Res Commun 449: 490-495.

Tsai CC, Chen YJ, Yew TL, Chen LL, Wang JY, Chiu CH, Hung SC (2011) Hypoxia inhibits senescence and maintains mesenchymal stem cell properties through down-regulation of E2A-p21 by HIF-TWIST. Blood 117: 459-469.

Voskamp C, van de Peppel J, Gasparini S, Giannoni P, van Leeuwen J, van Osch G, Narcisi R (2020) Sorting living mesenchymal stem cells using a TWIST1 RNA-based probe depends on incubation time and uptake capacity. Cytotechnology 72: 37-45.

Wiley CD, Velarde MC, Lecot P, Liu S, Sarnoski EA, Freund A, Shirakawa K, Lim HW, Davis SS, Ramanathan A, Gerencser AA, Verdin E, Campisi J
(2016) Mitochondrial dysfunction induces senescence with a distinct secretory phenotype. Cell Metab 23: 303-314.

Xu M, Bradley EW, Weivoda MM, Hwang SM, Pirtskhalava T, Decklever T, Curran GL, Ogrodnik M, Jurk D, Johnson KO, Lowe V, Tchkonia T, Westendorf JJ, Kirkland JL (2017) Transplanted senescent cells induce an osteoarthritis-like condition in mice. J Gerontol A Biol Sci Med Sci 72: 780-785.

Zhu Y, Armstrong JL, Tchkonia T, Kirkland JL (2014) Cellular senescence and the senescent secretory phenotype in age-related chronic diseases. Curr Opin Clin Nutr Metab Care 17: 324-328.

Zuk PA, Zhu M, Mizuno H, Huang J, Futrell JW, Katz AJ, Benhaim P, Lorenz HP, Hedrick MH (2001) Multilineage cells from human adipose tissue: implications for cell-based therapies. Tissue Eng 7: 211-228.

\section{Discussion with Reviewer}

Elena Della Bella: Can the authors comment on the potential role of TWIST1 in stem cell maintenance? Authors: The present manuscript showed the role of TWIST1 in regulating senescence in MSCs, inducing a specific metabolic shift. Previously, Isenmann et al. (2009) have demonstrated that expansion capacity of MSCs is associated with TWIST1 expression. Later, Narcisi et al. (2015) have observed that MSCs treated with WNT3a during expansion maintain high levels of TWIST1 expression and have enhanced expansion and differentiation capacity. Also, MSCs differentially sorted for high TWIST1 expression have a higher expansion rate compared to controls cells from the same MSC donor (Voskamp et al., 2020). Moreover, silencing of TWIST1 during the expansion phase reduces proliferation and impairs the chondrogenic differentiation capacity, with a clear correlation between TWIST1 expression and chondrogenic differentiation capacity (Cleary et al., 2017). Overall, these and the findings of the present study highlight the importance of the transcription factor TWIST1 in regulating expansion rate, senescence and differentiation capacity of MSCs, possibly by regulating cellular metabolism.

Editor's note: The Scientific Editor responsible for this paper was Mauro Alini. 